\title{
In vitro antiretroviral activity and in vivo toxicity of the potential topical microbicide copper phthalocyanine sulfate
}

\author{
Ashley R. Styczynski ${ }^{1,24^{*}}$, Khandaker N. Anwar ${ }^{1}$, Habiba Sultana' ${ }^{1}$, Abdelhamid Ghanem', Nell Lurain ${ }^{3}$, Aishi Chua ${ }^{1}$,
} Mahmood Ghassemi ${ }^{1}$ and Richard M. Novak ${ }^{1}$

\begin{abstract}
Background: Copper has antimicrobial properties and has been studied for its activity against viruses, including HIV. Copper complexed within a phthalocyanine ring, forming copper (II) phthalocyanine sulfate (CuPcS), may have a role in microbicide development when used intravaginally.

Methods: CUPcS toxicity was tested against cervical epithelial cells, TZM-BL cells, peripheral blood mononuclear cells (PBMC), and cervical explant tissues using cell viability assays. In vivo toxicity was assessed following intravaginal administration of CUPCS in female BALB/C mice and measured using a standardized histology grading system on reproductive tract tissues. Efficacy studies for preventing infection with HIV in the presence of various non-toxic concentrations of CuPCS were carried out in TZM-BL, PBMC, and cervical explant cultures using HIV-1 BAL and various pseudovirus subtypes. Non-linear regression was applied to the data to determine the EC50/90 and CC50/90.
\end{abstract}

Results: CuPCS demonstrated inhibition of HIV infection in PBMCs at concentrations that were non-toxic in cervical epithelial cells and PBMCs with EC50 values of approximately $50 \mu \mathrm{g} / \mathrm{mL}$. Reproductive tract tissue analysis revealed no toxicity at $100 \mathrm{mg} / \mathrm{mL}$. Human cervical explant tissues challenged with HIV in the presence of CuPcS also revealed a dose-response effect at preventing HIV infection at non-toxic concentrations with an EC50 value of $65 \mu \mathrm{g} / \mathrm{mL}$.

Conclusion: These results suggest that CUPCS may be useful as a topical microbicide in concentrations that can be achieved in the female genital tract.

\section{Background}

The need for an effective microbicide to prevent sexual transmission of HIV is a well-understood holy grail in prevention efforts. Beyond effectiveness, other important features of a microbicide include ease of application intravaginally and intrarectally, acceptable product characteristics, affordability, safety with repeated use, thermal and $\mathrm{pH}$ stability, and long-lasting effect. A successful microbicide should not disrupt the vaginal flora or mucosal epithelium or alter the $\mathrm{pH}$, which may predispose to

\footnotetext{
*Correspondence: Ashley.styczynski@gmail.com

'Department of Infectious Disease, University of Illinois at Chicago, Chicago,

IL 60612, USA

2Department of Internal Medicine, George Washington University,

Washington, DC 20037, USA

Full list of author information is available at the end of the article
}

additional infections [1]. Other features of more debatable value include non-coital dependence and opportunity for covert use. A microbicide that could dually protect against other sexually transmitted infections or prevent pregnancy may be especially desirable as these conditions increase risk of HIV transmission [2-4].

Copper has known bactericidal, fungicidal, and virucidal properties [5-7]. In vitro, copper-based compounds have been shown to prevent HIV infection through several mechanisms: irreversible inactivation of the essential HIV-1 enzyme protease [8], induction of free radical damage to nucleic acids [9], prevention of p24 production and syncytia formation in HIV-infected cells [9], inhibition of gp120 binding [10,11], and prevention of viral fusion [11]. 
Most copper-induced insults to cells are the result of free radical damage to biomolecules [7], which can be countered by eukaryotic cells through mechanisms that sequester, expel, or inactivate the copper ions or efficiently repair the damage [12]. Free copper ions diffusing throughout the vagina have the potential to produce reactive species that could damage the integrity of the vaginal epithelial cell barrier by overwhelming cell repair mechanisms or by interfering with protective microflora [5]. However, copper ions complexed within larger molecules such as sulfonated phthalocyanines (CuPcS) might prevent the production of such reactive species while also precluding absorption across the epithelial barrier and intracellular penetration.

Previous studies have demonstrated that $\mathrm{CuPcS}$ both protects against HIV infection of human $\mathrm{T}$ cells and elicits HIV inactivation in vitro [9, 11, 13-15]. It has also been shown to be non-toxic against Lactobacillus spp., the primary protective vaginal bacteria [14]. Additionally, it prevents cell-associated virus transmission and demonstrates effectiveness in preventing HIV transmission in general throughout a broad $\mathrm{pH}$ range, as occurs in the vagina [14]. Although the copper and phthalocyanine groups account for most of the HIV-preventing activity, the sulfate groups may afford additional protection against HIV infection by blocking both the endocytic and receptor-mediated pathways that HIV can utilize to infect cells $[16,17]$. The mechanisms by which CuPcS is known to prevent HIV infection include interference with viral envelope attachment to cell receptors and inhibition of viral entry into cells [14]. In a similar way, copper-impregnated filters have been tested in clinical trials to inactivate HIV in breast milk of HIV-positive mothers [15].

This study examines the feasibility of using $\mathrm{CuPcS}$ as a novel microbicide. $\mathrm{CuPcS}$ has not previously been studied in vivo. Using the established approach for preclinical development of microbicides, the product was tested for toxicity against epithelial cells as well as efficacy in peripheral blood mononuclear cells and TZM-BL cells. Mice and cervical explants provided models for toxicity and efficacy, respectively.

\section{Results and discussion}

Toxicity in cell cultures. Nontoxic concentrations of CuPcS were determined by exposing ME-180, TZM-BL, and PBMC cell lines to various concentrations of the compound. CC50 values were determined by applying non-linear regression to the data (Fig. 1). The ME-180 and TZM-BL cell lines demonstrated similar levels of toxicity with CC50s of $662.6 \mu \mathrm{g} / \mathrm{mL}$ and $543 \mu \mathrm{g} / \mathrm{mL}$, respectively. The CC50 of PBMCs could not be determined as this level of toxicity was never observed. Visual inspection of epithelial cell lines using a light microscope

\section{CuPcS Toxicity in Cervical Epithelial Cells and PBMCs}

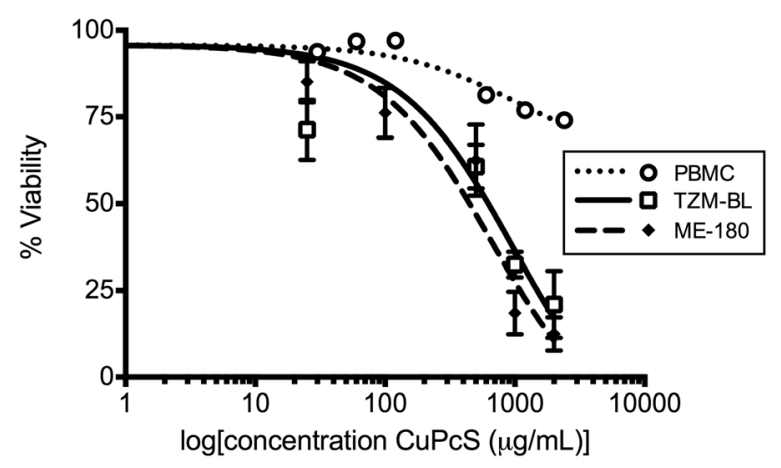

Fig. 1 CuPcS Toxicity in Cervical Epithelial Cells and PBMCs. Copper phthalocyanine sulfate (CUPCS) was combined with two cervical epithelial cell lines (ME-180 and TZM-BL) and peripheral blood mononuclear cells (PBMC) at increasing concentrations in quadruplicate. Toxicity was measured as percent viable cells determined by MTT assay or trypan blue exclusion with epithelial cells or PBMCs, respectively, after $48 \mathrm{~h}$ of incubation with CUPCS. A dose response effect is observed with increasing concentrations. CC50 values: $\mathrm{TZM}-\mathrm{BL}=973.7$,

and $\mathrm{ME}-180=662.6$

demonstrated slight disruption of epithelial layer integrity at concentrations of 1000 and $2000 \mu \mathrm{g} / \mathrm{mL}$.

Antiviral activity in TZM-BL cells. Antiviral activity of $\mathrm{CuPcS}$ in TZM-BL cells was determined by pre-treating pseudoviruses with varying nontoxic concentrations of $\mathrm{CuPCS}$ and then incubating with TZM-BL cells. A doseresponse effect was observed with increasing concentrations of $\mathrm{CuPcS}$ (Fig. 2). Non-linear regression models were used to determine EC50 and EC90 values (Table 1). Results were within one order of magnitude across the various pseudovirus strains.

Antiviral activity in PBMCs. PBMCs were combined with HIV-1 $1_{\text {BAL }}$ and nontoxic concentrations of CuPcS. A dose-response effect was observed with increasing

\section{Effect of CuPcS on Pseudovirus Infection of TZM-BL Cells}

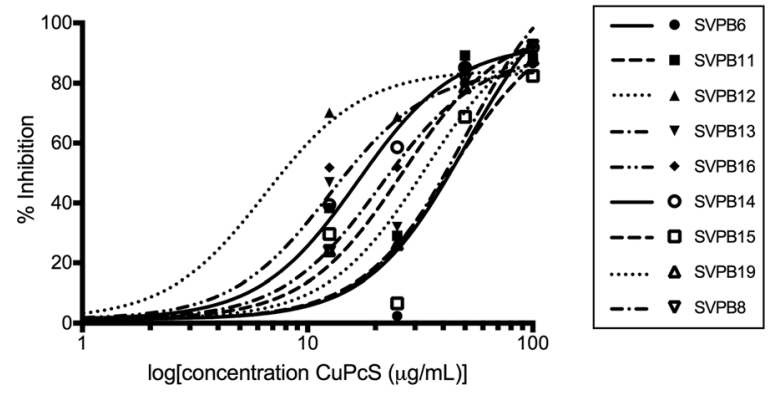

Fig. 2 Effect of CuPcS on Pseudovirus Infection of TZM-BL Cells. Copper phtahlocyanine sulfate (CUPCS) was combined with nine different Subtype B, HIV-1 pseudoviruses for one hour prior to addition of TZM-BL cells. Level of infectivity was determined by using a p24 assay performed in triplicate and was observed to have dose-response effect 
Table 1 The EC50 and EC90 values for copper phthalocyanine sulfate (CUPCS) preventing HIV-1 pseudovirus infection of TZM-BL cells were determined with a nonlinear regression model and was comparable across pseudovirus subtypes

\begin{tabular}{lll}
\hline Efficacy for pre-treatment of HIV with CuPCS & \\
\hline & EC50 $\mu \mathrm{g} / \mathrm{ml}$ & EC90 $\mu \mathrm{g} / \mathrm{ml}$ \\
\hline SVPB6 & 50.32 & 151.6 \\
SVPB11 & 26.33 & 79.35 \\
SVPB12 & 6.467 & 19.49 \\
SVPB13 & 21.04 & 63.41 \\
SVPB16 & 12.59 & 37.94 \\
SVPB14 & 16.67 & 50.24 \\
SVPB15 & 43.93 & 132.4 \\
SVPB19 & 33.24 & 100.2 \\
SVPB8 & 49.92 & 150.4 \\
\hline
\end{tabular}

concentration (Fig. 3). Non-linear regression models were used to calculate EC50 and EC90 (Table 2). Values were similar regardless of the order of combination except when HIV was pre-treated with $100 \mu \mathrm{g} / \mathrm{mL} \mathrm{CuPcS}$ and then combined with PBMCs and additional CuPcS, which was designed to assess irreversible virucidal activity of the compound. Pre-treatment of virus resulted in nearly complete inhibition regardless of post-treatment concentration.

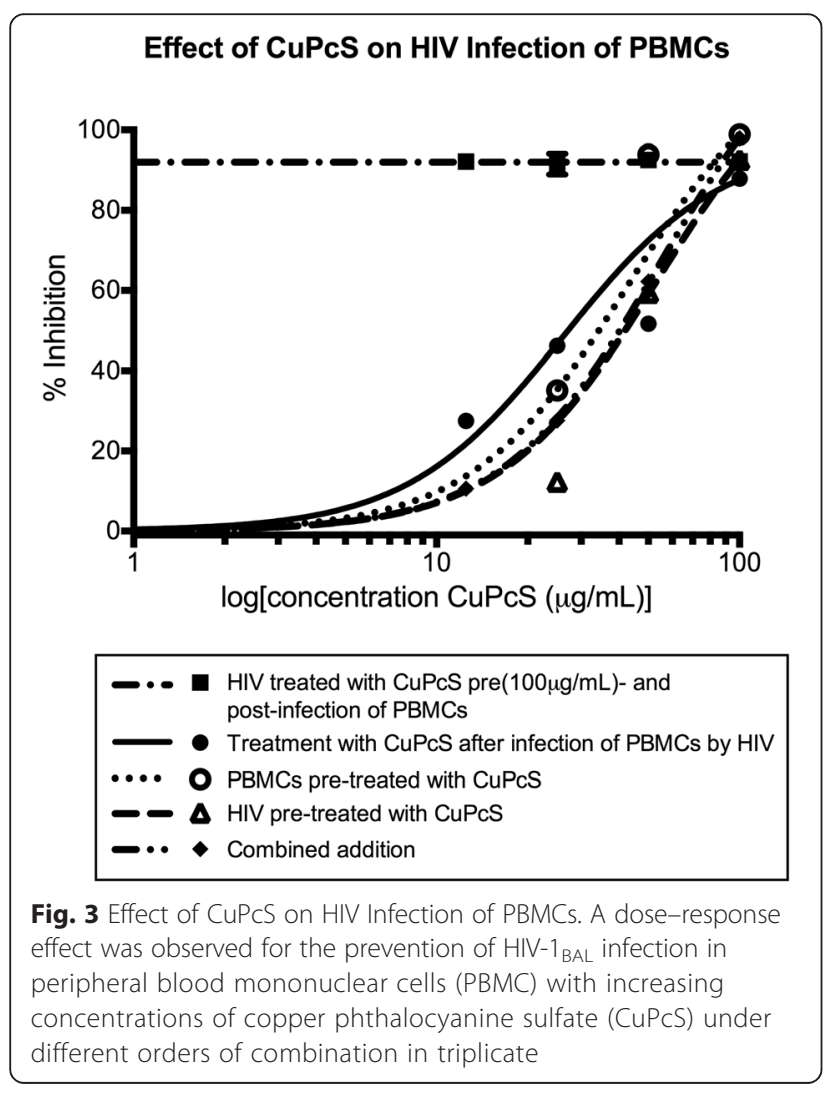

Table 2 The concentrations at which 50 and $90 \%$ of infections are prevented under the various conditions of copper phthalocyanine sulfate (CUPCS) exposure: HIV pre-treated with CuPCS; peripheral blood mononuclear cells (PBMC) pre-treated with CUPCS; simultaneous addition of HIV, PBMCs, and CuPCS; and pre-incubation of HIV and PBMCs with subsequent addition of CUPCS

CuPCS Inhibition of HIV-1 BAL $_{\text {Infection of PBMCS }}$

\begin{tabular}{lll}
\hline & EC50 $\mu \mathrm{g} / \mathrm{ml}$ & EC90 $\mu \mathrm{g} / \mathrm{ml}$ \\
\hline HIV pre-treated & 53.31 & 184.7 \\
PBMCs pre-treated & 42.96 & 147.2 \\
CuPCS added post-infection & 26.11 & 215.3 \\
Combined addition & 54.72 & 186.7 \\
Pre $(100 \mu \mathrm{g} / \mathrm{mL})$ - and post-treatment & Undefined & Undefined \\
\hline
\end{tabular}

Toxicity in mice. Of the 39 mice evaluated histologically, one of the Group $1(N=3)$ control mice, was eliminated due to the presence of bilateral, granulosa cell tumors in the ovary. For the remaining 38 animals, Group $2(N=12) 1 \%$ Carbopol gel, Group $3(N=12)$ $10 \mathrm{mg} / \mathrm{ml} \mathrm{CuPcS}$ in $2 \%$ Carbopol gel, and Group $4(N=$ 12) $100 \mathrm{mg} / \mathrm{ml} \mathrm{CuPcS}$ in $2 \%$ Carbopol gel, standard histologic guidelines were used to determine the stage of estrous prior to evaluating the average number and type of leukocytes in the lamina propria of the uterus and vagina (Additional file 1: Table S1). In the diestrus phase, on average, there were small and small-medium numbers of leukocytes in the lamina propria of the vagina in Groups 3 and $4(10 \mathrm{mg} / \mathrm{ml}$ and $100 \mathrm{mg} / \mathrm{ml} \mathrm{CuPcS}$, respectively), and small, small-medium, and medium numbers of leukocytes in the lamina propria of the vagina in Groups 1 and 2 (no $\mathrm{CuPcS}$ ) (Additional file 2: Table S2). In the proestrus phase, on average, there were occasional, small, and smallmedium numbers of leukocytes in the lamina propria of the vagina in Groups 3 and $4(10 \mathrm{mg} / \mathrm{ml}$ and $100 \mathrm{mg} / \mathrm{ml}$ $\mathrm{CuPcS}$, respectively), and small and small-medium numbers of leukocytes in the lamina propria of the vagina in Groups 1 and 2 (no CuPcS) (Additional file 3: Table S3). Sample histology photos are demonstrated in Fig. 4. The results strongly suggest that there is no significant difference within or between treatment groups, when segregated by estrous phase, in the level of leukocytic infiltration in the lamina propria of the vagina or uterus when comparing animals treated with $10 \mathrm{mg} / \mathrm{ml}$ and $100 \mathrm{mg} / \mathrm{ml} \mathrm{CuPcS}$ to animals treated with $1 \%$ Carbopol gel alone or with no intervention. However, further studies are needed with larger numbers of animals in each estrous phase to definitively document a lack of statistical significance.

Toxicity in cervical explant tissues. Cervical explant tissues were assayed for toxic effects of CuPcS using a MTT assay. Because the study was performed on tissues previously infected with HIV after exposure to $\mathrm{CuPcS}$, 


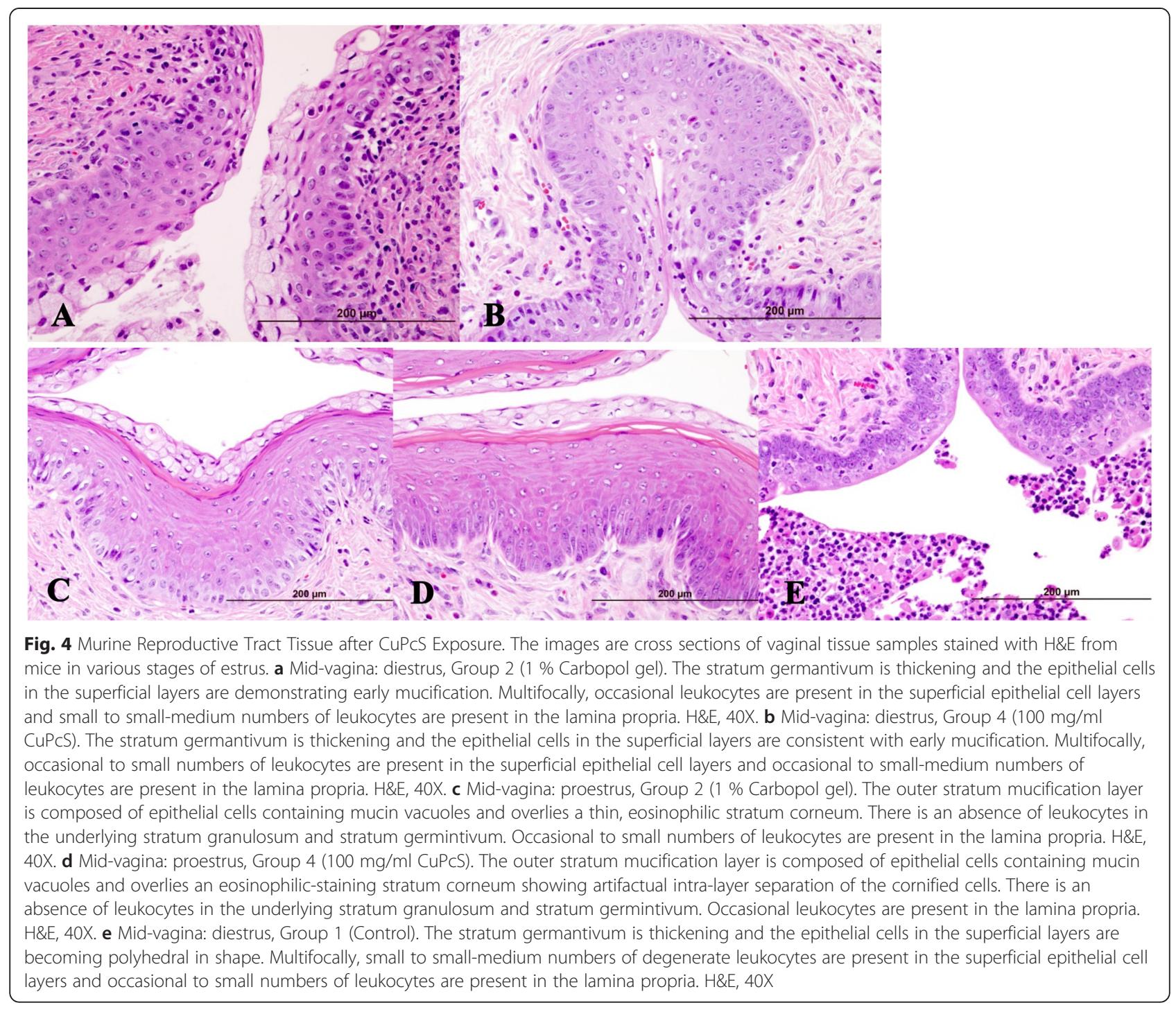

the assay was intended to provide a qualitative assessment of toxicity. The OD/mg tissue remained above the $50 \%$ level. There was no observed loss of tissue viability over the seven days of exposure with increasing concentrations of CuPcS (Additional file 4: Table S4).

Antiviral activity in cervical explant tissues. Cervical tissue was incubated with $\mathrm{CuPcS}$ suspended in cell medium for three hours before the addition of HIV- $1_{\mathrm{BAL}}$ and tested for infection at days 3, 5, and 7 with continued exposure to CuPcS. Data from days 5 and 7 were combined as these results were unlikely to contain residual inoculum and would represent cumulative p24 production since the supernatant was changed after each sampling. Using a non-linear regression model, the EC50 for the combined data on days 5 and 7 was determined to be $65.46 \mu \mathrm{g} / \mathrm{mL}$, and the EC90 was $118.3 \mu \mathrm{g} / \mathrm{mL}$. Percent inhibition was calculated based on reduction in p24 concentration compared to controls. Statistically significant inhibition of HIV infection was observed for increasing concentrations of $\mathrm{CuPcS}$ above $50 \mu \mathrm{g} / \mathrm{mL}(p<0.05)$ (Fig. 5).

The results of the cell-based toxicity experiments reveal CC50 values comparable to other studies with values consistently greater than $500 \mu \mathrm{g} / \mathrm{mL}[11,14]$. The in vitro EC50 values are within a log of previously reported values $[10,11,14]$. Reasons for the variability in efficacy may include differences in product purity and preparation, various HIV or pseudo-virus strains tested, and laboratory equipment calibration. This is the first published study to have investigated CuPcS in ex vivo and in vivo models. Previous pre-clinical studies that have shown promise for further development may not have been pursued given an increased focus by researchers and funders on developing microbicides based on known anti-retroviral therapies.

A long-acting microbicide would have sustained contact with the epithelium, potentiating the opportunity 


\section{Inhibition of HIV Infection in Cervical Explants}

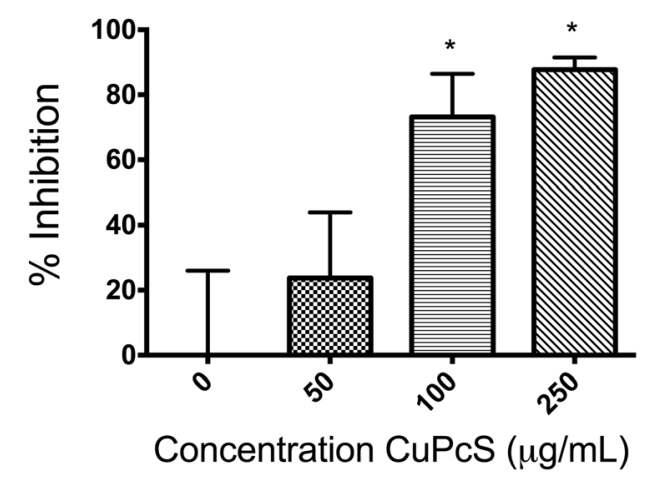

Fig. 5 Inhibition of HIV Infection in Cervical Explants. The increasing effectiveness of copper phthalocyanine sulfate (CUPCS) at preventing HIV-1 BAL infection of cervical explants with increasing concentrations of CuPcS is presented with standard error bars. Tissues were tested in sets of 4 or 8 at each concentration. Asterisks denote statistically significant differences in inhibition between concentrations of CuPcS using a one-way ANOVA test $(p<0.05)$

for toxic effects to be seen. This study addresses this issue by extending the time of incubation of $\mathrm{CuPcS}$ with cell lines to $48 \mathrm{~h}$, observing toxicity to cervical explants over seven days, and exposing mice to daily $\mathrm{CuPcS}$ administration for one week. Notably, the lack of observed toxicity occurred despite pre-treating the mice with medroxyprogesterone to enhance their susceptibility to toxic effects by thinning the epithelium.

Toxicity was observed at increased concentrations in the epithelial cell lines, though no gross toxicity was seen at any concentration in mice. This difference may be attributable to the inherent biological protective factors of the vaginal mucosal environment such as a circulating immune response and interplay of vaginal secretions and microflora [18], or it may be a limitation of the study design itself. It is unclear how the in vitro therapeutic index of approximately 100 would translate in vivo as no significant toxicity was seen in nonpolarized cervical explants or at concentrations up to $100 \mathrm{mg} / \mathrm{mL}$ in the mouse model. However, it should be noted that mouse models are an imperfect representation of the human female genital tract, and further studies using rabbit vaginal irritation models and primates should be performed to better address this issue before carrying out human studies.

Different methods were used to determine the results (MTT assay versus trypan blue exclusion) because the MTT assay requires the addition and removal of solutions at several steps along with subsequent washings to remove the highly pigmented $\mathrm{CuPcS}$ that might interfere with the assay. Without adherence of the PBMCs, too many cells were lost to obtain an accurate reading of viability by spectrophotometry. Trypan blue exclusion is often considered an inexact method of assessing viability. However, other studies have demonstrated equivalent results between MTT assays and trypan blue exclusion [18]. Similarly, the results in the present study were comparable among the cell lines regardless of the method used. Though the compound has a prominent blue color at high concentrations, it did not interfere with the MTT assay in controls after adding additional wash steps. One limitation of the data is the assessment of the epithelial integrity. Future studies should include measurements of transepithelial electrical resistance as a means of quantifying epithelial disruption, in particular, because previous sulfate-based microbicides have demonstrated clinical failure as a result of epithelial compromise [19].

A microbicide must also be non-immunogenic in the reproductive tract as immunologic responses to microbicide exposure may recruit more inflammatory cells to the mucosal epithelium, which would provide a larger number of permissive cells at the epithelial barrier at risk of infection [20]. This study showed no increase in the number of leukocytes observed over controls in the reproductive tract tissues of mice.

Susceptible CD4 cells in subcutaneous tissue are considered an important component of transmitting HIV across the epithelial barrier to the blood stream and are primary targets for HIV infection [21]. Thus, preventing infection of these crucial carriers may significantly reduce HIV acquisition. In this study, efficacy in preventing infection of PBMCs produced an expected dose-response effect of $\mathrm{CuPcS}$. With one exception, viral concentrations on day 5 and 6 under the various conditions were nearly equivalent indicating that the order of exposure is not critical. Thus, there may be multiple mechanisms by which $\mathrm{CuPcS}$ inhibits HIV infection. The scenario with pre- and posttreatment of HIV resulted in consistent inhibition regardless of the concentration added in the post-treatment step. This may represent irreversible inactivation of the virus by $\mathrm{CuPcS}$ because no viral activity returned following removal of the initial compound. Because the preincubation of PBMCs and HIV for one hour prior to CuPcS demonstrated dose-response inhibition, $\mathrm{CuPcS}$ may also be acting at a later stage in the viral life cycle. The CuPcS is not anticipated to have interfered with the p24 assay or the viability of the cells because incubation of PBMCs with $\mathrm{CuPcS}$ followed by triple washing and the addition of an HIV standard produced the same results as adding that standard to PBMCs alone.

\section{Conclusions}

In this study we demonstrate that $\mathrm{CuPcS}$ has activity against HIV-1 in the range of concentrations that are nontoxic to cervical epithelial cells, PBMCs, and cervical 
explant tissues. Likewise, CuPcS has a broad safety range in cervical explants and the genital tract of mice. This study enhances previous findings by replicating in vitro data and expanding to include both in vivo and ex vivo models [8-11, 13-15]. While these data represent preliminary investigations, the results are promising, and $\mathrm{CuPcS}$ should be considered for further evaluation as a potential topical microbicide against HIV.

Useful areas of potential investigation to expand the scope of this study could include the following: measuring effects using other virus clades and cell lines; evaluating for cell-associated virus transmission to see how CuPcS affects the transfer of virus from dendritic cells to PBMCs; conducting more sensitive tests of proinflammatory effects; and performing assays for altered susceptibility, including intrarectally, to subsequent viral challenge in animal models to demonstrate toxicity.

The field of HIV treatment has long battled against the rapid rise in drug resistance. Increasing access to pharmaceuticals in the global population has resulted in greatly expanded life expectancy for those who have been infected with HIV. However, the inconsistent supply of medications coupled with the challenge of adherence to a lifetime of daily drug therapy has caused an increase in primary acquisition and superinfection with resistant viruses worldwide [22-28]. Though partial efficacy to many of the first-line drugs remains, this may pose a mounting challenge to prevention efforts. Thus, it is critical for the field to diversify its prevention portfolios to include innovations such as the one presented here that may interfere at several points of HIV infection and transmission. Furthermore, until there is a prevention modality that meets all the complex needs and demands of the population at risk, researchers and funders should continue to pursue an array of prevention technologies.

\section{Materials and methods Ethics statement}

PBMCs were obtained through phlebotomy with consent from healthy, HIV-negative volunteers in accordance with a protocol approved by the Institutional Review Board at the University of Illinois at Chicago (Protocol number: 2009-0737). Ectocervical tissue was obtained with consent from women undergoing hysterectomies for benign disease under a protocol approved by the Institutional Review Board at Rush University Medical Center, Chicago, IL. All research with mice conformed to the Animal Care Policy set forth by the University of Illinois at Chicago Animal Care Committee, which is accredited by the Association for Assessment and Accreditation of Laboratory Animal Care - International, and in accordance with the Guide for the Care and Use of Laboratory Animals of the National Institutes of
Health. The protocol was approved by the Office of Animal Care and Institutional Biosafety Committee at the University of Illinois at Chicago (Permit Number: 201101675). Measures to minimize suffering during toxicity studies in the mice included daily observation for signs of mucocutaneous irritation, weight loss, or other evidence of distress, which would be indications to remove the animals from further participation in the study. All animal handlers were trained by the veterinarian of the Animal Care Committee in the careful handing of the animals during administration of the microbicide to place light traction on the back while elevating the hind legs using the tail. Microbicide was administered quickly and gently using new, sterilized, intact pipettes in under five seconds per mouse, minimizing total handling time. This process was determined to be a non-painful and minimally distressing means of microbicide administration by the veterinarian of the Animal Care Committee. Mice were sacrificed using $\mathrm{CO}_{2}$ narcosis, which is considered a humane and acceptable method of euthanasia through its painless induction of somnolence.

\section{Test compound}

Copper(II) phthalocyanine-tetrasulfonic acid tetrasodium salt (CuPcS) (molecular weight 988.28) was obtained from Sigma-Aldrich (St. Louis, MO). Stock solutions were created using PBS with a $\mathrm{pH}$ of 7.2 at a concentration of $100 \mu \mathrm{g} / \mathrm{mL}$. This was used for all studies on cell and tissue cultures.

\section{Cells}

Human cervical ME-180 epithelial cells were obtained from ATCC (Manassas, VA, lot no. 57758662) and maintained in McCoy's 5a medium supplemented with $10 \%$ heat-inactivated fetal bovine serum, 1 \% L-glutamine, $100 \mathrm{U} / \mathrm{mL}$ penicillin, and $100 \mu \mathrm{g} / \mathrm{mL}$ streptomycin. The TZM-BL cell line, an engineered He-La cervical cell line that expresses CD4, CXCR4, and CCR5 and contains Tat-inducible Luc and B-Gal reporter genes, was obtained through the NIH AIDS Reagent Program, NIAID, NIH: TZM-BL from Dr. John C. Kappes, Dr. Xiaoyun Wu and Tranzyme Inc. [29], and maintained in Dulbecco's Modified Eagle Medium (DMEM) supplemented as above with $1 \%$ sodium pyruvate. PBMCs were isolated using gradient-density centrifugation. The cells were cultivated in complete RPMI medium supplemented as with DMEM for three days and stimulated with $10 \mu \mathrm{g} / \mathrm{mL}$ phytohemagglutinin (PHA) and $10 \%$ rIL-2 (obtained through the NIH AIDS Reagent Program, Division of AIDS, NIAID, NIH: Human rIL-2 from Dr. Maurice Gately, Hoffmann - La Roche Inc. [30]). PBMCs were then washed and suspended in complete RPMI with 10 \% IL-2. All cells were maintained at $37^{\circ} \mathrm{C}$ in $5 \% \mathrm{CO}_{2}$. 


\section{HIV-1 stocks}

The HIV-1 $1_{\mathrm{BAL}}$, a CCR5 tropic virus, was obtained through the NIH AIDS Reagent Program, NIAID, NIH: HIV-1 $1_{\text {BAL }}$ from Drs. Suzanne Gartner, Mikulas Popovic, and Robert Gallo [31]. Stocks were created by combining the virus with PHA-stimulated PBMCs, adding IL-2, and collecting supernatant at days 5 and 7 . Viral concentrations were determined using the p24 Antigen Capture Assay Kit provided by the National Cancer Institute (NIH, Bethesda, MD).

\section{Pseudovirus preparation}

The Standard Reference Panel of Subtype B HIV-1 Env clones was obtained through the AIDS Reagent Program, NIAID, NIH from the following contributors: QH0692 clone 42 (SVPB6), PVO clone 4 (SVPB11), TRO clone 11 (SVPB12), AC10.0 clone 29 (SVPB13) and SC422661 clone B (SVPB8) from Drs. David Montefiori and Feng Gao; pREJO4541 clone 67 (SVPB16), pRHPA4259 clone 7 (SVPB14) from Drs. B.H. Hahn and J.F. SalazarGonzalez; pTHRO4156 clone 18 (SVPB15) and pCAAN5342 clone A2 (SVPB19) from Drs. B.H. Hahn and D.L. Kothe [32-34]. The env expression vector pNL43.Luc.R-.E- was also obtained through the same NIH AIDS Reagent Program from Dr. Nathaniel Landau.

Stocks of single-round-infection HIV-1 Env pseudovirus were produced by cotransfecting $293 \mathrm{~T}$ cell monolayers at $70 \%$ confluency in 6-well plates with $3 \mu \mathrm{g}$ pNL4-3.Luc.R-.E- and 0.5-4.0 $\mu \mathrm{g}$ env clone plasmid with the transfection reagent polyethylenimine. Pseudovirus stocks were harvested $48 \mathrm{~h}$ post-transfection and filtered with a $0.45-\mu \mathrm{m}$ filter. To test infectivity, TZM-BL cells were inoculated with each of the stocks. Infectivity was determined after $72 \mathrm{~h}$ by measurement of chemiluminescence produced by at least a 5-fold increase in luciferase activity relative to the background chemiluminescence of the vector alone. Stock aliquots were stored at $-80{ }^{\circ} \mathrm{C}$ until use.

\section{Toxicity in cell culture}

Fifty thousand ME-180 or TZM-BL cells were added to each well of a 96-well plate and incubated for $24 \mathrm{~h}$. $\mathrm{CuPcS}$ dissolved in PBS was added to the wells with culture medium in quadruplicate to produce final concentrations of $0-2000 \mu \mathrm{g} / \mathrm{mL}$ CuPcS. Cells were incubated with $\mathrm{CuPcS}$ for $48 \mathrm{~h}$ at $37{ }^{\circ} \mathrm{C}$ and then washed with fresh medium. MTT (3-(4,5-dimethylthiazol-2-yl)-2,5-diphenyltetrazolium bromide) Cell Proliferation Assay Kit was obtained from Cayman Chemical (Ann Arbor, MI; lot no. 0417667), and the MTT reagent was added to each well and incubated for $3 \frac{1}{2}$ hours. Cells were manually washed with Hank's balanced salt solution before crystal-dissolving solution was added. The plate was incubated at room temperature in dark conditions for $90 \mathrm{~min}$. Cells were examined using a light microscope for preserved confluence and adherence. Viability was determined through light absorbances read by Vmax Kinetic Microplate Reader (Molecular Devices Corporation, Sunnyvale, CA) at $562 \mathrm{~nm}$. Because of the nonadherence of PBMCs and subsequent difficulty washing out the residual pigmented $\mathrm{CuPcS}$, toxicity in PBMCs was estimated with trypan blue exclusion.

\section{Antiviral activity in TZM-BL cells}

TZM-BL cells were seeded in 96-well plates $\left(5 \times 10^{3}\right.$ cells per well) and incubated at $37{ }^{\circ} \mathrm{C}$ in a $5 \% \mathrm{CO}_{2}$ atmosphere for $24 \mathrm{~h}$. CuPcS was diluted serially with DMEM and incubated in triplicate with pseudoviruses SVPB6, SVPB11, SVPB12, SVPB13, SVPB16, SVPB14, SVPB15, SVPB19, and SVPB8 (at dilutions equivalent to a 5-15 fold increase in luminescence over background) at $37{ }^{\circ} \mathrm{C}$ for $1 \mathrm{~h}$. The mixture was added to TZM-BL cells $(100 \mu \mathrm{L} /$ well $)$, and the plates were further incubated at $37^{\circ} \mathrm{C}$ for an additional hour. Then $100 \mu \mathrm{L}$ DEAE Dextran was added to each well, and the plates were incubated at $37^{\circ} \mathrm{C}$ for $48 \mathrm{~h}$. Cells were lysed by adding $100 \mu \mathrm{L}$ Luciferase Cell Culture Lysis 5x Reagent (Promega, Madison, WI) to each of the wells. Cell extracts were measured for luminescence using Monolight 3010 Luminometer (Pharmingen, San Diego, CA).

\section{Antiviral activity in PBMCs}

HIV-1 $1_{\text {BAL }}$ was grown in PBMCs as described above. Antiviral activity of $\mathrm{CuPcS}$ was determined using p24 ELISA. CuPcS was combined with 1,225 pg virus (measured as p24) and 15,000 PBMCs in 96-well plates under various conditions in triplicate: 1) PBMCs were infected with HIV for one hour, then incubated with $\mathrm{CuPcS}$ for two hours; 2) virus was pre-treated with $\mathrm{CuPcS}$ for one hour before adding PBMCs with or without additional $\mathrm{CuPcS}$; 3) PBMCs were pre-treated with $\mathrm{CuPcS}$ for one hour before the addition of virus; and 4) PBMCs, virus, and $\mathrm{CuPcS}$ were simultaneously combined. In all conditions, PBMCs were subsequently washed to remove compound and residual virus, and new medium was added. Supernatant was collected on days 4-6 and tested for viral replication. To quantify virus present, p24 concentrations were determined and used to calculate inhibition as percent reduction in $\mathrm{p} 24$ concentrations compared with controls.

\section{Product development}

A common polymer used as a microbicide matrix is Carbopol $^{\circledR}$. Carbopol 940 was selected because of its ability to sustain the viscosity of a thick gel over a broad range of alterations in temperature and $\mathrm{pH}$ to aid in retention within the vagina. However, to offset the partial reduction in viscosity posed by increasing concentrations of $\mathrm{CuPcS}$, higher percentages of Carbopol were used for 
higher concentrations of $\mathrm{CuPcS}$. The final formulations ranged from 1.5-3 \% Carbopol with $250 \mu \mathrm{g} / \mathrm{mL}$ $100 \mathrm{mg} / \mathrm{mL} \mathrm{CuPcS}$. These compounds were used exclusively for the studies of toxicity in mice. The compound was neutralized with triethanolamine to a $\mathrm{pH}$ around 7 .

\section{Toxicity in mice}

Six- to ten-week old female BALB/C mice were obtained from Charles River Laboratories (Frederick, MD). The mice received subcutaneous injections of $3 \mathrm{mg}$ medroxyprogesterone acetate (Greenstone LLC, Peapack, NJ) five days prior to microbicide application. The purpose of the medroxyprogesterone in this study was to mimic the luteal phase of the menstrual cycle by thinning the epithelial lining, thus rendering it more susceptible to potential irritants. Mice received daily intra-vaginal applications of $40 \mu \mathrm{L}$ of CuPcS in Carbopol using $50-\mu \mathrm{L}$ Wiretrol glass pipettes (Drummond-Scientific, Broomall, PA) over seven days. Pipettes were manipulated in and out five times to ensure distribution of the microbicide throughout the vagina. Mice were examined daily for signs of genital irritation and then sacrificed with $\mathrm{CO}_{2}$ narcosis at 1,2, or 3 weeks post-microbicide application. Female mouse reproductive tracts were harvested and fixed in $10 \%$ neural buffered formalin for $8-12 \mathrm{~h}$, washed with phosphate buffer solution and stored in $70 \%$ ethanol prior to processing. Sections of ovary, uterus, cervix and vagina were exposed to routine processing, embedded in paraffin and sectioned at 5 microns. Tissue sections were stained with hematoxylin and eosin and evaluated by a veterinary pathologist. Due to the variability of leukocytic infiltrates in the rodent uterus and vagina during the estrous cycle, standard histologic guidelines were used to determine the stage of estrous for each animal [35]. A 7 tier numerical grading scale, i.e., grades 1-7: $1=$ occasional $(0-3$ cells per hpf), $2=$ small $(4-10$ per hpf $), 3=$ small-medium (11-20 per hpf), $4=$ medium $(21-30$ per hpf), $5=$ medium-large (31-40 per hpf), $6=$ large $(41-50$ per hpf) and $7=$ marked ( $>50$ per hpf), was used to evaluate the average number of leukocytes in the lamina propria of the uterus and vagina. In randomly selected sites, the number of leukocytes observed in 4-6 fields, were counted at 400X magnification. The numerical field values were then averaged and recorded as a range for within and between group comparisons.

\section{Antiviral activity in cervical explant tissues}

Single, non-polarized pieces of ectocervical tissue approximately $3 \mathrm{~mm}^{3}$ in size were placed in inner wells of 48-well culture plates [36]. CuPcS stock solution was diluted using RAFT medium (DMEM containing 24\% Ham's F-12 medium, $4 \mathrm{mg} / \mathrm{mL}$ insulin, 100 Units $/ \mathrm{mL}$ Pen/Strep, $50 \mu \mathrm{g} / \mathrm{mL}$ gentamicin, $10 \% \mathrm{FBS}$, and $20 \mathrm{mM}$ HEPES buffer). Tissues were incubated with each of the
CuPcS concentrations for three hours before inoculation with $\mathrm{HIV}-1_{\mathrm{BAL}}$ stock at $5,880 \mathrm{TCID}_{50}$. For each condition there were 4 to 8 tissue replicates. Three days following inoculation, tissues were washed twice with RPMI and transferred to a 48-well plate with fresh medium containing appropriate concentrations of $\mathrm{CuPcS}$. Supernatant was removed five hours after the initial wash and replaced with fresh medium. The medium was sampled and exchanged at 5 days postinfection. A third supernatant sample was obtained at day 7 post infection. Supernatant samples were assayed for p24 using the HIV-1 p24 ELISA Kit (catalog \# NEK05000, PerkinElmer, Waltham, MA).

\section{Toxicity in cervical explant tissues}

MTT assays were performed on the tissues previously exposed to CuPcS and challenged with HIV to monitor viability. Single explants were added to individual wells of a 48-well plate containing $500 \mu \mathrm{g} / \mathrm{mL}$ of MTT in DMEM in sets of 4 or 8 at each concentration. The explants were incubated at $37{ }^{\circ} \mathrm{C}$ for three hours and then transferred to 48 -well plates containing $1 \mathrm{~mL}$ methanol per well. The plates were incubated at room temperature overnight in the dark. For analysis, explants were blotted to remove excess medium and placed in pre-weighed tubes to determine and record the tissue weight. The absorbance of three replicates of the MTT supernatant fluid was determined at $570 \mathrm{~nm}$ on a CERES $900 \mathrm{UV}$ HDi plate reader (Bio-Tek Instruments, Winooski, VT).

\section{Statistical analysis}

The effects of CuPcS on toxicity and efficacy were analyzed using non-linear regression modeling and used to calculate EC50s/90s and CC50s/90s. A two-tailed $t$-test was applied to mean values for percent inhibition in the cervical explant models, and a one-way analysis of variance was applied to assess for statistical significance. The statistical calculations were performed using GraphPad Prism, Version 6.0d (GraphPad Software, San Diego, CA).

\section{Availability of supporting data}

The data supporting the results of this article are included within the article and its additional files.

\section{Additional files}

Additional file 1: Table S1. Number of Animals by Estrous Phase and Treatment Group. The number of female mice in each treatment group is subdivided based on stage of estrus. (DOC $28 \mathrm{~kb}$ )

Additional file 2: Table S2. Average Numerical Grade of Leukocytes in the Vaginal Lamina Propria during Diestrus by Group. The number of female mice in diestrus is listed according to average leukocyte grade by treatment group. (DOC $43 \mathrm{~kb}$ )

Additional file 3: Table S3. Average Numerical Grade of Leukocytes in the Vaginal Lamina Propria during Proestrus by Group. The number of 
female mice in proestrus is listed according to average leukocyte grade by treatment group. (DOC $44 \mathrm{~kb}$ )

Additional file 4: Table S4. Average Percent Viability of Cervical Explant Cells with Increasing Concentration of CuPcS. Toxicity as measured using MTT assay is presented for cervical explant cells over seven days of exposure to CuPCS. Percent viability was determined as a function of optical density compared with controls. Concentrations were tested in quadruplicate. (DOC $25 \mathrm{~kb}$ )

\section{Competing interests}

The authors declare that they have no competing interests.

\section{Authors' contributions}

AS designed the study under the direction of RN and carried out studies of toxicity in cell lines, participated in efficacy studies in PBMCs, and performed all statistical analyses. MG participated in the collection and isolation of PBMCs. KA, AG, and HS cultivated viral stocks and determined efficacy in TZM-BL cells and all pseudovirus studies. NL performed toxicity and efficacy studies in cervical explant tissues. AC designed the Carbopol formulation to serve as the CUPCS vehicle. All authors read and approved the final manuscript.

\section{Authors' information}

RN is an infectious disease specialist and Department Chair of the Division of Infectious Diseases at UIC College of Medicine with extensive experience in HIV research. MG is the lead researcher of the Division of Infectious Diseases at UIC College of Medicine. NL is a senior HIV researcher at Rush University Medical Center.

\section{Acknowledgements}

The authors would like to acknowledge the Bill and Melinda Gates' Foundation for their generous support of this research through a Grand Challenges Exploration Grant. The funders had no role in the design of the study; data collection, analysis, or interpretation; writing of the manuscript; or decision to submit the manuscript for publication. The authors would also like to acknowledge the contributions of Susan M. Ball-Kell, DVM, PhD, Veterinary Diagnostic Laboratory, University of Illinois College of Veterinary Medicine at Urbana-Champaign, IL, for processing and analysis of histology specimens.

\section{Author details}

${ }^{1}$ Department of Infectious Disease, University of Illinois at Chicago, Chicago, IL 60612, USA. ${ }^{2}$ Department of Internal Medicine, George Washington University, Washington, DC 20037, USA. ${ }^{3}$ Department of Infectious Disease, Rush University, Chicago, IL 60612, USA. ${ }^{4} 755$ North Ave NE \#1319, Atlanta, GA 30306, USA.

\section{Received: 19 December 2014 Accepted: 13 August 2015} Published online: 30 August 2015

\section{References}

1. Hemelaar J, Gouws E, Ghys P, Osmanov S. Global and regional distribution of HIV-1 genetic subtypes and recombinants in 2004. AIDS. 2006;20:13-23.

2. Chesson HW, Pinkerton SD. Sexually transmitted diseases and the increased risk for HIV transmission: implications for cost-effectiveness analyses of sexually transmitted disease prevention interventions. J Acquir Immune Defic Syndr. 2000;24:48-56.

3. Fleming DT, Wasserheit JN. From epidemiological synergy to public health policy and practice: the contribution of other sexually transmitted diseases to sexual transmission of HIV infection. Sex Transm Infect. 1999;75:3-17.

4. Gray RH, Li X, Kigozi G, Serwadda D, Brahmbhatt G, Wabwire-Mangen F, et al. Increased risk of incident HIV during pregnancy in Rakai, Uganda: a prospective study. Lancet. 2005;366:1182-8.

5. Borkow G, Gabbay J. Putting copper into action: copper-impregnated products with potent biocidal activities. FASEB J. 2004;18:1728-30.

6. Borkow G, Gabbay J. Copper as a biocidal tool. Curr Med Chem. 2005;12:2163-75.

7. Coyle B, Kinsella P, McCann M, Devereux M, O'Connor R, Clynes M, et al. Induction of apoptosis in yeast and mammalian cells by exposure to 1,10-phenanthroline metal complexes. Toxicol In Vitro. 2004;18:63-70.
8. Karlstrom AR, Levine RL. Copper inhibits the protease from HIV-1 by both cysteine-dependent and cysteine-independent mechanisms. Proc Natl Acad Sci U S A. 1991;88:5552-6.

9. Sagripanti JL, Lightfoote MM. Cupric and ferric ions inactivate HIV. AIDS Res Hum Retroviruses. 1996;12:333-6.

10. François KO, Pannecouque C, Auwerx J, Lozano V, Pérez-Pérez MJ, Schols D, et al. The phthalocyanine prototype derivative Alcian Blue: the first synthetic agent with selective anti-human immunodeficiency virus activity due to its gp120 glycan-binding potential. Antimicrob Agents Chemother. 2009;53:4852-9.

11. Vzorov A, Marzilli LG, Compans RW, Dixon DW. Prevention of HIV-1 infection by phthalocyanines. Antiviral Res. 2003:59:99-109.

12. Laval J. Role of DNA repair enzymes in the cellular resistance to oxidative stress. Pathol Biol (Paris). 1996;44:14-24.

13. Longinova NV, Koval'chuk TV, Polozov Gl, Osipovich NP, Rytik PG, Kucherov I, et al. Synthesis, characterization, antifungal and anti-HIV activities of metal(II) complexes of 4,6-di-tert-butyl-3-[(2-hydroxyethyl)thio]benzene-1,2diol. Eur J Med Chem. 2008:43:1536-42.

14. Vzorov AN, Bozja J, Dixon DW, Marzilli LG, Compans RW. Parameters of inhibition of HIV-1 infection by small anionic microbicides. Antiviral Res. 2007;73:60-8.

15. Borkow G, Lara HH, Covington CY, Nyamathi A, Gabbay J. Deactivation of HIV-1 in medium by copper-oxide containing filters. Antimicrob Agents Chemother. 2007:52:518-25.

16. Huskens D, Vermeire K, Profy AT, Schols D. The candidate sulfonated microbicide, PRO, has potential multiple mechanisms of action against HIV-1. Antiviral Res. 2000;2009(84):38-47.

17. Scordio-Bello IA, Mosoian A, He C, Chen Y, Cheng Y, Jarvis GA, et al. Candidate sulfonated and sulfated topical microbicides: comparison of anti-human immunodeficiency virus activities and mechanisms of action. Antimicrob Agents Chemother. 2005;49:2607-15.

18. Seth R, Yang S, Choi S, Sabean M, Roberts EA. In vitro assessment of copper-induced toxicity in the human hepatoma line, Hep G2. Tox In Vitro. 2004;18:501-9.

19. Mesquita PM, Cheshenko N, Wilson SS, Mohak M, Guzman E, Fakioglu E, et al. Disruption of tight junctions by cellulose sulfate facilitates HIV infection: model of microbicide safety. J Infect Dis. 2009;200:599-608.

20. Cummins JE, Dezzuttii CS. Sexual HIV-1 transmission and mucosal defense mechanisms. AIDS Rev. 2000;2:144-54

21. Miller CJ, Shattock RJ. Target cells in vaginal HIV transmission. Microbes Infect. 2003;5:59-67.

22. Viani RM, Peralta L, Aldrovandi G, Kapogiannis BG, Mitchell R, Spector SA, et al. Prevalence of primary HIV-1 drug resistance among recently infected adolescents: a multicenter adolescent medicine trials network for HIV/AIDS interventions study. J Infect Dis. 2006;194:1505-9.

23. UK Collaborative Group on Monitoring the Transmission of HIV Drug Resistance. Analysis of prevalence of HIV-1 drug resistance in primary infections in the United Kingdom. BMJ. 2001;322:1087-8.

24. Hamers RL, Wallis CL, Kityo C, Siwale M, Mandaliya K, Conradie F, et al. HIV-1 drug resistance in antiretroviral-naïve individuals in sub-Saharan Africa after rollout of antiretroviral therapy: a multicenter observational study. Lancet Infect Dis. 2001;11:750-9.

25. Descamps D, Chaix ML, Montes B, Pakianather S, Charpentier C, Storto A, et al. Increasing prevalence of transmitted drug resistance mutations and non-B subtype circulation in antiretroviral-naïve chronically HIV-infected patients from 2001 to 2006/2007 in France. J Antimicrob Chemother. 2010;65:2620-7.

26. Little SJ, Holte S, Routy JP, Daar ES, Markowitz M, et al. Antiretroviral-drug resistance among patients recently infected with HIV. N Engl J Med. 2002;347:385-94.

27. Sungkanuparph S, Oyomopito R, Sirivichayakul S, Sirisanthana T, Li PC, Kantipong $\mathrm{P}$, et al. HIV-1 drug resistance mutations among antiretroviralnairve HIV-1-infected patients in Asia: results from the TREAT Asia studies to evaluate resistance-monitoring study. Clin Infect Dis. 2011;52:1053-7.

28. Smith DM, Wong JK, Hightower GK, Ignacio CC, Koelsch KK, Petropoulos CJ, et al. HIV drug resistance acquired through superinfection. AIDS. 2005;19:1251-6.

29. Platt EJ, Wehrly K, Kuhmann SE, Chesebro B, Kabat D. Effects of CCR5 and CD4 cell surface concentrations on infections by macrophagetropic isolates of human immunodeficiency virus type 1. J Virol. 1998;72:2855-64.

30. Lahm HW, Stein S. Characterization of recombinant human IL-2 with micromethods. J Chromatogr. 1985;326:357-61. 
31. Gartner S, Markovits P, Markovitz DM, Kaplan MH, Gallo RC, Popovic M. The role of mononuclear phagocytes in HTLV-III/LAV infection. Science. 1986;233:215-9.

32. Li M, Gao F, Mascola JR, Stamatatos L, Polonis VR, Koutsoukos M, et al. Human immunodeficiency virus type 1 env clones from acute and early subtype B infections for standardized assessments of vaccine-elicited neutralizing antibodies. J Virol. 2005;79:10108-25.

33. Wei XI, Decker JM, Liu H, Zhang Z, Arani RB, Kilby JM, et al. Emergence of resistant human immunodeficiency virus type 1 in patients receiving fusion inhibitor (T-20) monotherapy. Antimicrob Agents Chemother. 2002;46:1896-905.

34. Wei XI, Decker JM, Wang S, Hui H, Kappes JC, Wu X, et al. Antibody neutralization and escape by HIV-1. Nature. 2003;422:307-12.

35. Westwood FR. The female rat reproductive cycle: a practical histological guide to staging. Toxicol Pathol. 2008;36:375-84.

36. Fox-Canale AM, Hope TJ, Martinson J, Lurain JR, Rademaker AW, Bremer JW, et al. Human cytomegalovirus and human immunodeficiency virus type-1 co-infection in human cervical tissue. Virology. 2007;369:55-68.

\section{Submit your next manuscript to BioMed Central and take full advantage of:}

- Convenient online submission

- Thorough peer review

- No space constraints or color figure charges

- Immediate publication on acceptance

- Inclusion in PubMed, CAS, Scopus and Google Scholar

- Research which is freely available for redistribution 